UCRL-JC-128870

PREPRINT

Performance of Smoothing by Spectral Dispersion (SSD) with Frequency Conversion on the Beamlet Laser for the National Ignition Facility

J. E. Rothenberg, B. Moran, P. Wegner, T. Weiland

This paper was prepared for submittal to the Conference on Lasers and Electro-Optics '98

San Francisco, CA

May 5-7, 1998

November 4, 1997

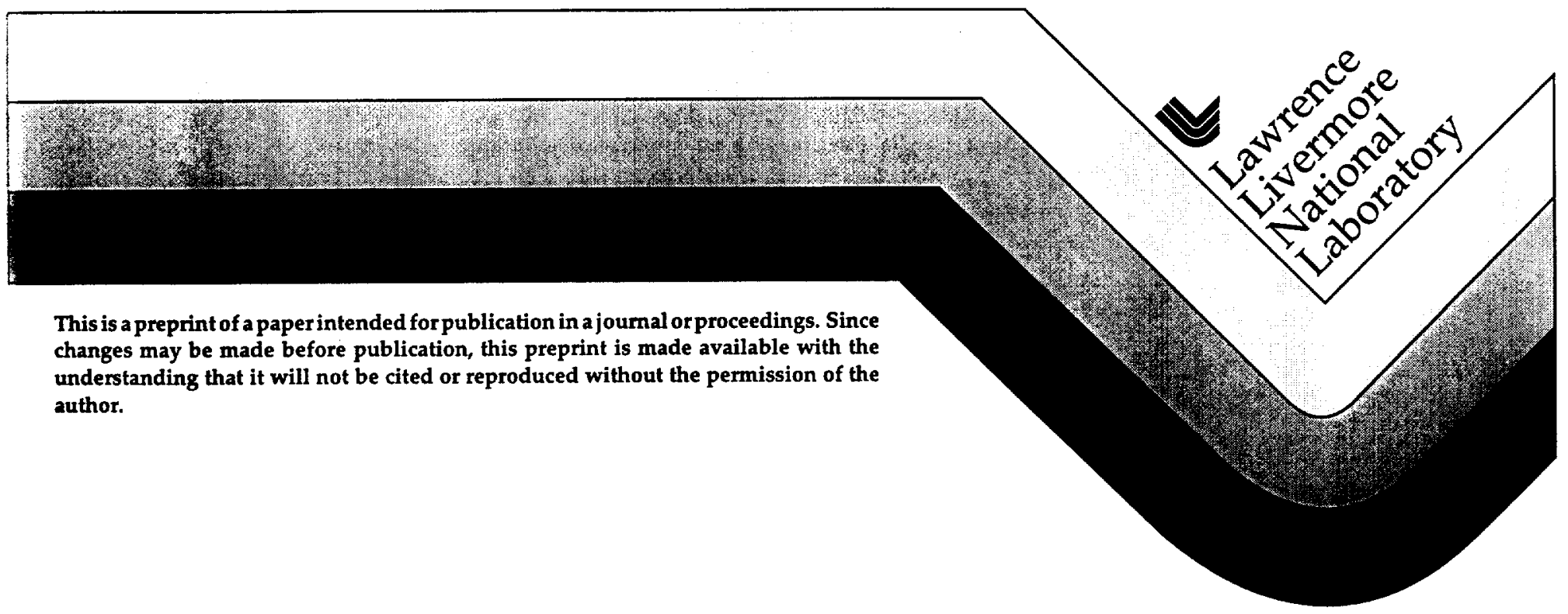




\section{DISCLAIMER}

This document was prepared as an account of work sponsored by an agency of the United States Government. Neither the United States Government nor the University of California nor any of their employees, makes any warranty, express or implied, or assumes any legal liability or responsibility for the accuracy, completeness, or usefulness of any information, apparatus, product, or process

disclosed, or represents that its use would not infringe privately owned rights. Reference herein to any specific commercial product, process, or service by trade name, trademark, manufacturer, or otherwise, does not necessarily constitute or imply its endorsement, recommendation, or favoring by the United States Government or the University of California. The views and opinions of authors expressed herein do not necessarily state or reflect those of the United States Government or the University of California, and shall not be used for advertising or product endorsement purposes. 


\title{
Performance of Smoothing by Spectral Dispersion (SSD) with Frequency Conversion on the Beamlet Laser for the National Ignition Facility
}

\author{
Joshua E. Rothenberg, Bryan Moran, Paul Wegner, and Tim Weiland
}

\author{
Lawrence Livermore National Laboratory, L-439 \\ P. O. Box 808, Livermore, CA 94551 \\ Phone: (510) 423-8613, FAX: (510) 422-5537 \\ Email: JRI@ @LNL.GOV
}

\begin{abstract}
Simulations and ongoing measurements indicate that SSD results in small degradation to the near field beam quality. The measured effect of SSD bandwidth on conversion to the third harmonic and smoothing of the target illumination will also be described.
\end{abstract}

This work was performed under the auspices of the U. S. Department of Energy by Lawrence Livermore National Laboratory under Contract No. W-7405-Eng-48. 


\title{
Performance of Smoothing by Spectral Dispersion (SSD) with Frequency
}

Conversion on the Beamlet Laser for the National Ignition Facility

Joshua E. Rothenberg, Bryan Moran, Paul Wegner, and Tim Weiland,

\author{
Lawrence Livermore National Laboratory, L-439 \\ P. O. Box 808, Livermore, CA 94551 \\ Phone: (510) 423-8613, FAX: (510) 422-5537
}

\section{Email: JR1 @ LLNL.GOV}

Inertial confinement fusion (ICF) utilizing direct or indirect laser drive requires the target illumination to be uniform over a wide range of spatial frequencies. A number of approaches have been suggested to achieve the desired level of illumination uniformity. ${ }^{1-4}$ Angular dispersion of phase modulated (FM) light (termed smoothing by spectral dispersion - SSD) 4 is attractive for ICF using glass lasers, since pure phase modulation preserves the uniform intensity profiles necessary for high power laser amplification. 1D SSD has been demonstrated on the NOVA laser, 5 however the National Ignition Facility (NIF) will require much more efficient and reliable operation. Therefore, it is of interest to investigate the performance of ID SSD on the Beamlet laser, which is a NIF prototypical multipass laser system.

Numerical simulations of the Beamlet laser using PROP92 have been performed for $1 \mathrm{~ns}$ pulses with $\pm 200 \mu \mathrm{rad}$ main cavity spatial filter pinholes. These simulations show that the critical parameter for the laser performance is the amount of additional divergence imposed on the beam by SSD in comparison to the size of the spatial filter pinholes. Figure 1 shows the results of the PROP92 calculations of the contrast of the near field intensity at $1 \omega$ as a function of pulse 
energy and SSD divergence. One sees that the degradation of the beam is enhanced slight with increasing amounts of SSD. For example, with SSD divergence of $25 \mu \mathrm{rad}$, the contrast calculated is the same as a beam without SSD, but with pulse energy less by about $5 \%$.

Figure 2 shows measurements of the $1 \omega$ Schlieren far field taken on Beamlet for a $3.5 \mathrm{KJ}, 1 \mathrm{~ns}$ pulse with (left) and without (right) SSD present. In this measurement the divergence of SSD was $\sim 25 \mu \mathrm{rad}$. One sees that frequency components generated by Gibbs phenomena near the pinhole edge (indicated by the circle) are not significantly enhanced with or without SSD present. Near field measurements at this pulse energy also show that SSD does not significantly impact the beam contrast, as predicted in Fig. 1. The only effect of SSD which is clearly apparent in Fig. 2 is that the speckle structure in the far field is smoothed in the vertical SSD direction, which is the desired effect on the illumination in the target plane. Measurements of the $1 \omega$ laser performance at higher energies and the $\sim 20 \mathrm{~ns}$ pulse lengths required for ignition will also be described.

The $1.053 \mu \mathrm{m}$ beam is converted to the thrid harmonic by a $11 / 9 \mathrm{~mm}$ pair of type I KDP / type II KD*P crystals. It is expected that the harmonic conversion efficiency will be reduced by the addition of the large bandwdith associated with SSD. Figure 3 shows the calculation 6 of the peak conversion efficiency in the presence of SSD bandwidth for a fundamental input intensity of $3.0 \mathrm{GW} / \mathrm{cm} 2$. Measurements of the conversion efficiency, bandwidth at the third harmonic, and the effect of SSD on the Beamlet focal distribution (smoothing of speckle and broadening of the focal envelope) will also be discussed. 
This work was performed under the auspices of the U. S. Department of Energy by Lawrence Livermore National Laboratory under Contract No. W7405-Eng-48.

\section{References}

1. R. H. Lehmberg and S. P. Obenschain, Optics Comm. 46, 27 (1983) and R. H. Lehmberg and J. Goldhar, Fusion Technology 11, 532 (1987).

2. Y. Kato et al, Phys. Rev. Lett. 53, 1057 (1984).

3. D. Véron et al, Optics Comm. 65,42 (1988).

4. S. Skupsky et al, J. Appl. Phys. 66, 3456 (1989).

5. D. M. Pennington et al, Proc. Soc. Photo-Opt. Instrum. Eng. 1870, 175 (1993).

6. D. Eimerl, J. M. Auerbach, and P. W. Milloni, J. Mod. Opt. 42, 1037 (1995). 


\section{Figure Captions}

Figure 1: PROP92 calculations showing the contrast (RMS variation as a fraction of the average) of the near field intensity just after the transport spatial filter, at the end of a 1 ns pulse of varying energy, and with the indicated amount of SSD divergence. The cavity spatial filter is assumed to use $\pm 200 \mu \mathrm{rad}$ pinholes. The effect of SSD is to reduce the effective pulse energy where breakup occurs -by $\sim 5 \%$ for $25 \mu \mathrm{rad}$ of SSD and by $\sim 10 \%$ for $50 \mu \mathrm{rad}$ of SSD.

Figure 2: Measured Schlieren far field images of $1 \omega$ Beamlet beam for a $3.5 \mathrm{KJ}$, Ins pulse with (left) and without (right) SSD present. The ring shows the location of the cavity spatial filter pinhole edge. No additional nonlinear enhancement of angular components near the pinhole edge is apparent with SSD implemented. However, one sees the effect of smoothing of the speckle structure in the vertical SSD direction.

Figure 3: Calculation of the conversion efficiency from $1.053 \mu \mathrm{m}$ to $351 \mathrm{~nm}$ at $3.0 \mathrm{GW} / \mathrm{cm}^{2}$ as a function of the bandwidth at $1.053 \mu \mathrm{m}$, using a 11 $\mathrm{mm}$ type I KDP doubler and $9.0 \mathrm{~mm}$ type II KD*P tripler. 


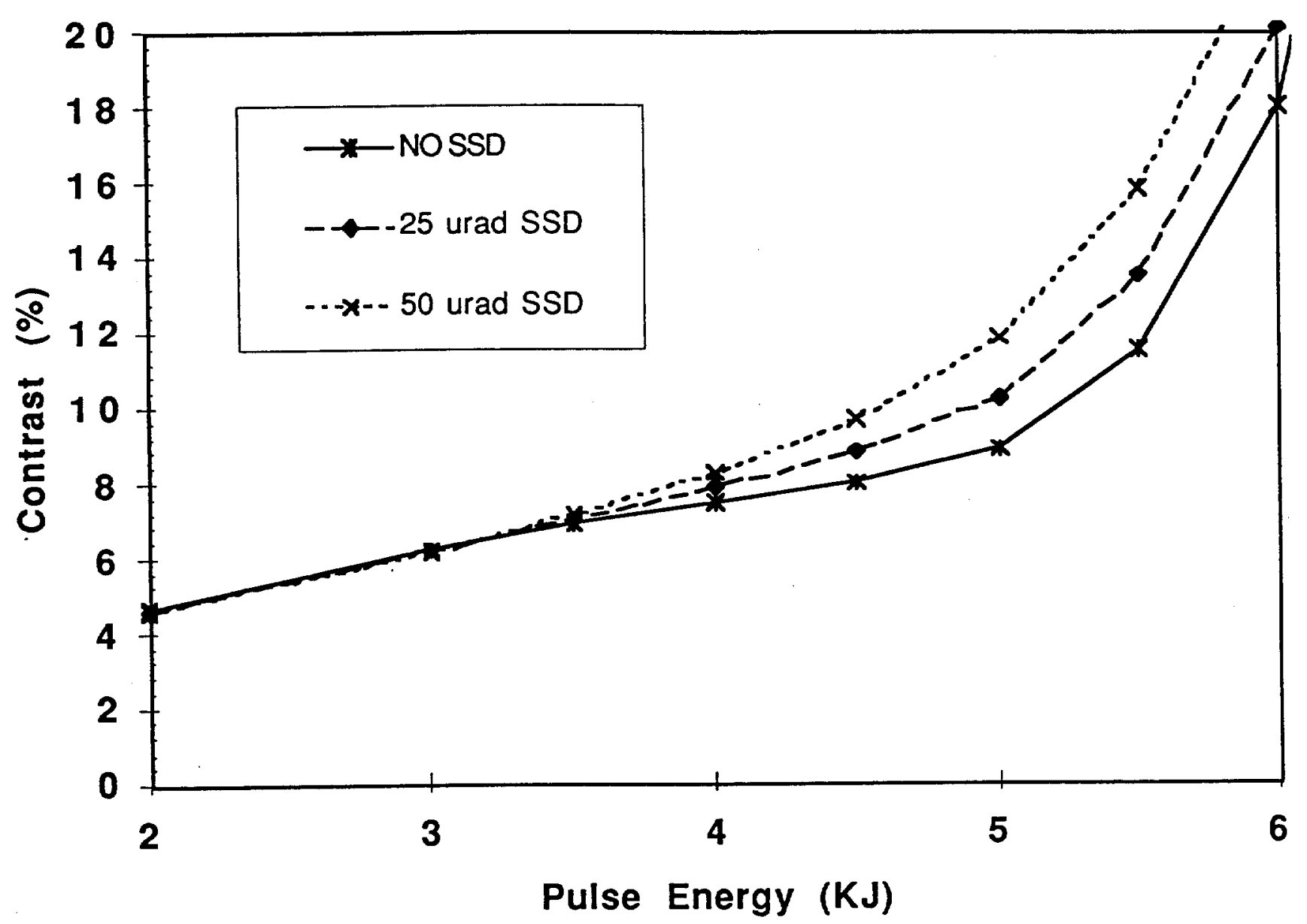

Figure 1: PROP92 calculations showing the contrast (RMS variation as a fraction of the average) of the near field intensity just after the transport spatial filter, at the end of a 1 ns pulse thergy, and with the indicated amount of SSD divergence. The cavity spatial filter is assumed to use $\pm 200 \mu \mathrm{rad}$ pinholes. The effect of SSD is to reduce the effective pulse energy where breakup occurs -by $\sim 5 \%$ for $25 \mu \mathrm{rad}$ of SSD and by $\sim 10 \%$ for $50 \mu \mathrm{rad}$ of SSD. 


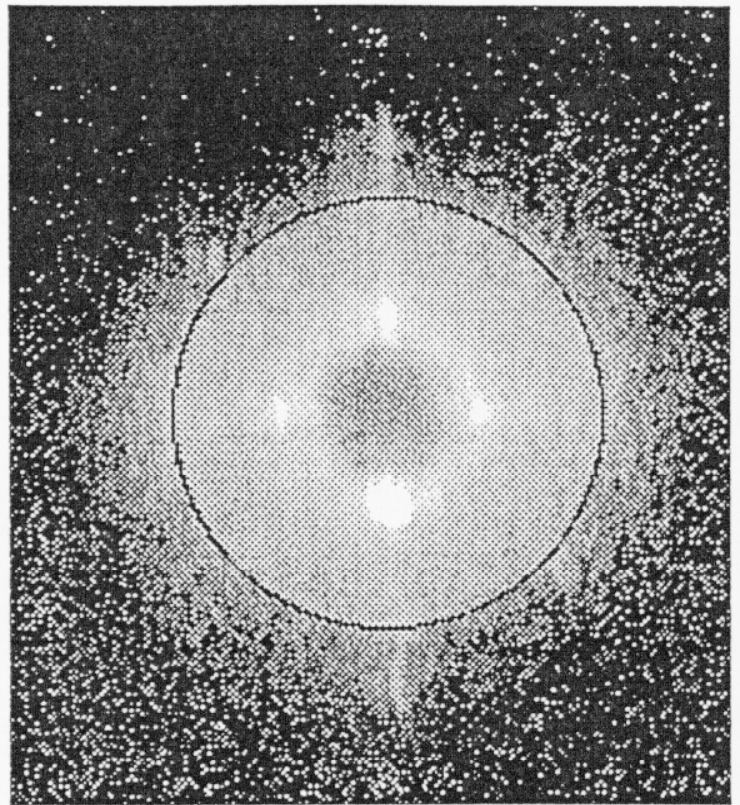

With SSD

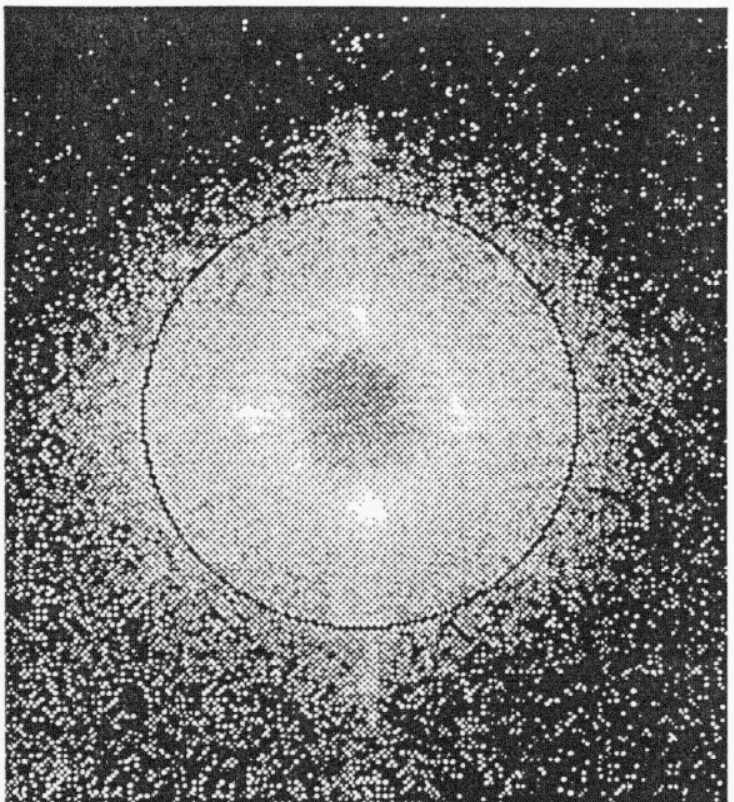

Without SSD

Figure 2: Measured Schlieren far field images of $1 \omega$ Beamlet beam for a $3.5 \mathrm{KJ}$, Ins pulse with (left) and without (right) SSD present. The ring shows the location of the cavity spatial filter pinhole edge. No additional nonlinear enhancement of angular components near the pinhole edge is apparent with SSD implemented. However, one sees the effect of smoothing of the speckle structure in the vertical SSD direction. 
1673.ps - J. E. Rothenberg et al, "Performance of Smoothing by Spectral Dispersion..."

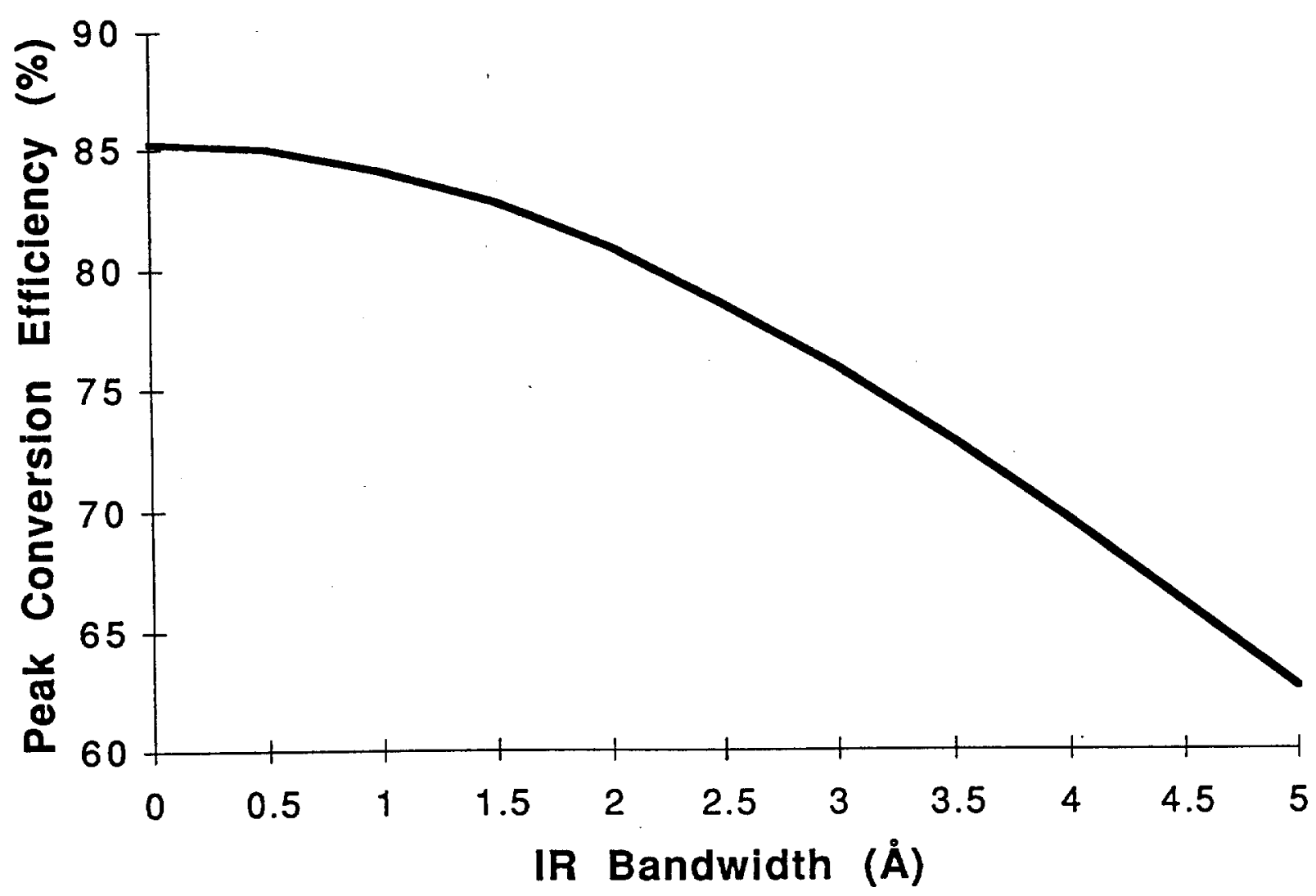

Figure 3: Calculation of the conversion efficiency from $1.053 \mu \mathrm{m}$ to $351 \mathrm{~nm}$ at inpt inters.ty $3.0 \mathrm{GW} / \mathrm{cm}^{2}$ as a function of the bandwidth at $1.053 \mu \mathrm{m}$, using a 11 $\mathrm{mm}$ type I KDP doubler and $9.0 \mathrm{~mm}$ type II KD*P tripler. 


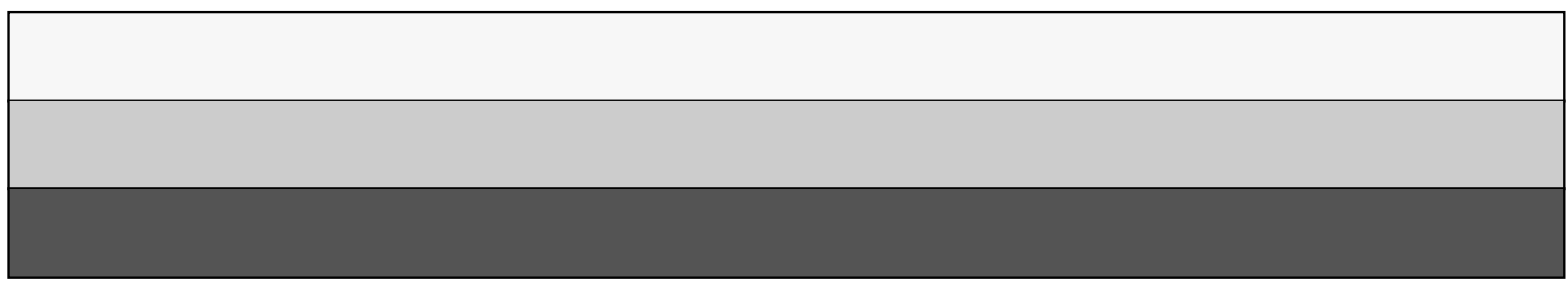

